\title{
Anchoring the potential energy surface of an important atmospheric van der Waals dimer, the $\mathrm{H}_{2} \mathrm{O} \cdots \mathrm{O}_{2}$ complex
}

Katelyn M. Dreux and Gregory S. Tschumper*

Department of Chemistry and Biochemistry

University of Mississippi, University, Mississippi 38677-1848 USA

${ }^{*}$ Corresponding author. Tel.:+1 662915 7301; fax: +1 6629157300.

E-mail address: tschumpr@olemiss.edu 


\begin{abstract}
The focus of this paper is the weakly-bound $\mathrm{H}_{2} \mathrm{O} \cdots \mathrm{O}_{2}$ van der Waals dimer. The global minimum has an electronic dissociation energy of $0.70 \mathrm{kcal} \mathrm{mol}^{-1}$ at the spin unrestricted $\operatorname{CCSD}(\mathrm{T})$ level of theory $(\mathrm{UCCSD}(\mathrm{T}))$ in conjunction with a correlation consistent quadruple-zeta basis set augmented with diffuse functions on all heavy atoms, denoted haQZ (i.e., cc-pVQZ for $\mathrm{H}$ and augcc-pVQZ for O). Eleven other stationary points are also characterized at the $\operatorname{UCCSD}(\mathrm{T}) /$ haQZ level of theory, all of which lie within $0.5 \mathrm{kcal} \mathrm{mol}^{-1}$ of the global minimum and have at least one imaginary frequency $\left(\mathrm{n}_{i} \geq 1\right)$. The spin unrestricted MP2 method (UMP2) yields very similar structures and energies for the twelve stationary points. However, the UMP2 vibrational frequencies provide a qualitatively different description of the potential energy surface (more than a single minimum), of the frequency shifts upon complexation and of the resulting infrared intensities of the complex. The UCCSD(T)/haQZ computations indicate only one of the twelve $\mathrm{H}_{2} \mathrm{O} \cdots \mathrm{O}_{2}$ structures is a minimum and that it exhibits appreciable infrared intensity for one of the lowest energy intermolecular vibrational modes, unlike the related $\mathrm{H}_{2} \mathrm{O} \cdots \mathrm{N}_{2}$ system.
\end{abstract}




\section{Introduction}

Earth's atmosphere is comprised of $78 \% \mathrm{~N}_{2}, 21 \% \mathrm{O}_{2}$, and less than $1 \%$ of other gases, under completely dry conditions [1]. The amount of water vapor in the atmosphere is variable at any given time, but typical values range from 1-4\% depending on temperature and altitude. Given the high abundances of $\mathrm{N}_{2}, \mathrm{O}_{2}$ and $\mathrm{H}_{2} \mathrm{O}$, along with water's propensity to form non-covalent complexes, the chemistry of van der Waals complexes plays an important role in the troposphere. $\left(\mathrm{H}_{2} \mathrm{O}\right)_{2}$ is a strong absorber of near infrared (IR) radiation, particularly in the $\mathrm{OH}$ stretching region $[2,3] \cdot \mathrm{H}_{2} \mathrm{O} \cdots \mathrm{O}_{2}$ and $\mathrm{H}_{2} \mathrm{O} \cdots \mathrm{N}_{2}$ have also been evaluated as enhanced absorbers of IR radiation [4-7]. Upon complexation, new intermolecular vibrational modes are formed between the fragments that could have appreciable IR activity. In addition, the monomer vibrations can be perturbed in the complex, leading to enhanced IR activity. An increase in the IR intensity of one or more vibrational modes of the fragments and/or a large IR intensity for any newly-formed intermolecular modes of the complex could point to enhanced greenhouse effects from these van der Waals complexes [4], but it is important to note that other changes, such as to the width of the vibrational transitions, can also affect radiative transfer. Large frequency shifts or IR intensity changes after dimerization could also be helpful for directly detecting a particular complex in the atmosphere or laboratory [5].

A number of prior studies of the $\mathrm{H}_{2} \mathrm{O} \cdots \mathrm{O}_{2}$ complex have utilized MøllerPlesset perturbation theory to characterize stationary points on the potential energy surface [4, 8-13]. The most extensive ab initio investigation of the potential energy surface examined twelve different structures of $\mathrm{H}_{2} \mathrm{O} \cdots \mathrm{O}_{2}$ at the MP2/aug-cc-pVTZ level of theory [8]. In some cases, quadratic configuration interaction or coupled-cluster single point energy computations (e.g. QCISD and CCSD) were also performed to recover more dynamical electron correlation which slightly reduced the dissociation energy of global minimum [5, 6, 1422]. Several studies also considered the multireference nature of $\mathrm{O}_{2}$, which has a ${ }^{3} \Sigma_{g}^{-}$ground state. However, the results from multi-reference computations were consistent with those from single-reference MP2 calculations [8, 11, 20].

The global minimum identified by these studies (structure I, shown in Fig. 1 ) is a $\mathrm{C}_{s}$ structure with a ${ }^{3} \mathrm{~A}^{\prime \prime}$ electronic state and an electronic dissociation energy well below $1 \mathrm{kcal} \mathrm{mol}^{-1}$. Most correlated wavefunction based methods with basis sets of at least triple-zeta quality yield dissociation energies for the global minimum of just over $0.7 \mathrm{kcal} \mathrm{mol}^{-1}[5,8]$. There is, however, significant variation in some intermolecular geometrical parameters of the optimized structures. The $\mathrm{OH} \cdots \mathrm{O}$ and $\mathrm{OO} \cdots \mathrm{H}$ angles (denoted $\alpha$ and $\beta$, respectively, in Fig. 1) exhibit variations of more than 20 degrees because the potential energy surface of $\mathrm{H}_{2} \mathrm{O} \cdots \mathrm{O}_{2}$ is very shallow $[6,11,20]$. Eleven other stationary points with $\mathrm{C}_{s}$ or $\mathrm{C}_{2 v}$ symmetry (structures II-XII, Fig. 1) have also been identified that are within $0.5 \mathrm{kcal} \mathrm{mol}^{-1}$ of the global minimum.

In this work, coupled-cluster theory (specifically the $\operatorname{CCSD}(\mathrm{T})$ method) is used to characterize these twelve stationary points on the potential energy surface of the $\mathrm{H}_{2} \mathrm{O} \cdots \mathrm{O}_{2}$ complex (Fig. 1), six $\mathrm{C}_{2 v}$ structures and six $\mathrm{C}_{s}$ structures 
(including the global minimum). Dissociation energies, geometrical parameters and harmonic vibrational frequencies of both the fragments and complex are compared to those from second-order Møller-Plesset perturbation theory. Frequency shifts and IR intensity changes are used to monitor changes in the spectroscopic fingerprints of each monomer species upon complexation. The IR intensities of the low-energy intermolecular vibrational frequencies $(<150$ $\mathrm{cm}^{-1}$ ) are also examined to discern the potential of the $\mathrm{H}_{2} \mathrm{O} \cdots \mathrm{O}_{2}$ complex to play a role as an enhanced absorber in the atmosphere. Our group performed a similar analysis of six key stationary points on the potential energy surface of $\mathrm{H}_{2} \mathrm{O} \cdots \mathrm{N}_{2}$ [7]. As such, this paper also provides a direct comparison of these two important complexes, $\mathrm{H}_{2} \mathrm{O} \cdots \mathrm{O}_{2}$ and $\mathrm{H}_{2} \mathrm{O} \cdots \mathrm{N}_{2}$.

\section{Computational Methods}

Full geometry optimizations and harmonic vibrational frequency computations were performed for each dimer structure and the isolated fragments with second order Møller-Plesset perturbation theory[23] and coupled-cluster method with single, double, and perturbative triple substitutions[24] using a spin unrestricted Hartree-Fock (UHF) reference wavefunction for all open-shell species $\left(\mathrm{O}_{2}\right.$ and $\left.\mathrm{H}_{2} \mathrm{O} \cdots \mathrm{O}_{2}\right)$ and a spin restricted Hartee-Fock (RHF) reference for the closed-shell systems $\left(\mathrm{H}_{2} \mathrm{O}\right)$. These computations were performed with the analytic gradients and Hessians available in CFOUR[25], and the corresponding results are labeled as UMP2 and UCCSD(T). All energies, optimized structures and harmonic vibrational frequencies were computed with the correlation consistent family of basis sets in which diffuse functions were added to the "heavy" (non-hydrogen) atoms (i.e. cc-pVXZ for $\mathrm{H}$ and aug-cc-pVXZ for $\mathrm{O}$ where $\mathrm{X}$ $=\mathrm{T}, \mathrm{Q}$, and 5$)$. These basis sets are denoted haXZ throughout the remainder of this manuscript. In addition, a series of single point MP2 and $\operatorname{CCSD}(\mathrm{T})$ energies were computed that employed a spin restricted Hartree-Fock (ROHF) reference for the open shell systems, (i.e. ROMP2 and ROCCSD(T)). Explicitly correlated F12 single point energies were also computed with the ha5Z basis set and associated default density fitting basis sets in the Molpro2010[26] program to estimate the complete basis set (CBS) limit. Partially spin-restricted explicitly correlated coupled-cluster computations (denoted ROCCSD(T)-F12) employ an ROHF reference, and a cluster operator that neglects some spin coupling in order to reduce spin contamination [27, 28]. Unrestricted explicitly correlated coupled-cluster computations (denoted $\operatorname{UCCSD}(\mathrm{T})-\mathrm{F} 12$ ) also used an ROHF reference, but the method is more susceptible to spin contamination because the unmodified cluster and spin-squared operators do not commute [27, 28]. The Gaussian09[29] software package was used for all UMP2 and ROMP2 calculations. All UCCSD $(\mathrm{T})$ and ROCCSD $(\mathrm{T})$ calculations were done using CFOUR, whereas Molpro2010 was used for the explictly correlated computations. Pure angular momentum functions $(5 d, 7 f, 9 g)$ were used rather than Cartesian functions $(6 d, 10 f, 15 g)$. All Cartesian forces associated with the optimized structures have been converged to less than $1 \times 10^{-4} \mathrm{E}_{h} / \mathrm{a}_{0}$. 


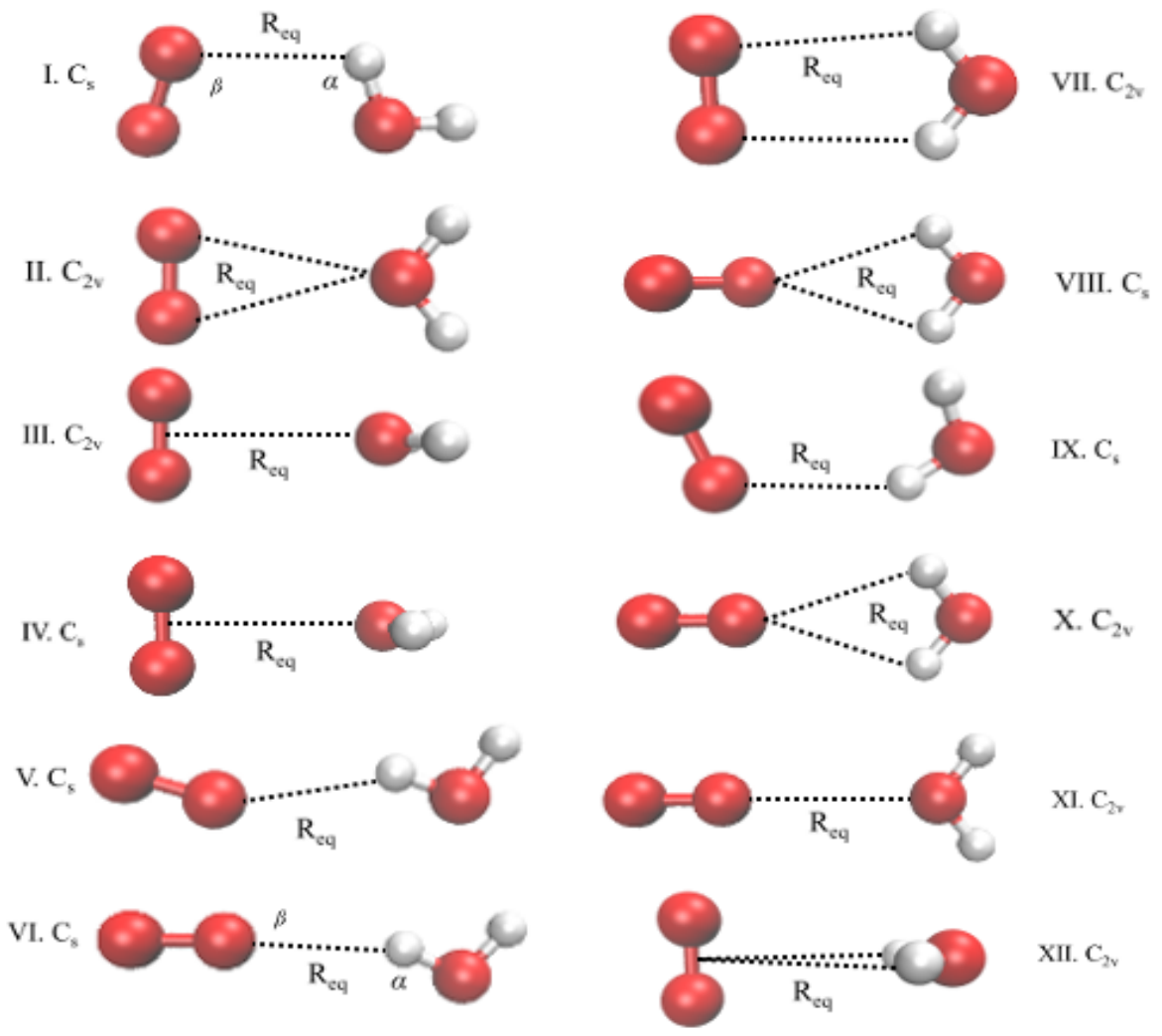

Figure 1: Twelve structures and point group symmetries of the $\mathrm{H}_{2} \mathrm{O} \cdots \mathrm{O}_{2}$ system along with select intermolecular parameters $\left(\mathrm{R}_{e q}, \alpha, \beta\right)$ described in the text.

\section{Results and Discussion}

\section{1. $\mathrm{O}_{2}$ and $\mathrm{H}_{2} \mathrm{O}$ Fragments}

Table 1 lists the intramolecular bond lengths and bond angle along with harmonic vibrational frequencies and IR intensities of $\mathrm{O}_{2}$ and $\mathrm{H}_{2} \mathrm{O}$. The differences between the optimized haTZ and haQZ bond lengths and bond angle are minimal, less than $0.006 \AA$ and $0.2^{\circ}$, and deviations between corresponding harmonic vibrational frequencies do not exceed $25 \mathrm{~cm}^{-1}$. Higher-order correlation effects have a more substational impact on the fragments, particularly for $\mathrm{O}_{2}$. Relative to the $\mathrm{UCCSD}(\mathrm{T})$ results, UMP2 overestimates the $\mathrm{OO}$ bond length by $0.01 \AA$ and underestimates the frequency by $120 \mathrm{~cm}^{-1}$ with both haTZ and haQZ basis sets. The deviations between MP2 and $\operatorname{CCSD}(\mathrm{T})$ for the $\mathrm{H}_{2} \mathrm{O}$ fragment are smaller, with maximum unsigned deviations of $0.001 \AA$ for the $\mathrm{OH}$ bond length, $0.1^{\circ}$ for the $\mathrm{HOH}$ angle, and $30 \mathrm{~cm}^{-1}$ for any frequency. At the $\operatorname{CCSD}(\mathrm{T}) /$ haQZ level, the largest IR intensity of $73 \mathrm{~km} \mathrm{~mol}^{-1}$ corresponds to 
the $\mathrm{HOH}$ bend at $1651 \mathrm{~cm}^{-1}$. For the twelve $\mathrm{H}_{2} \mathrm{O} \cdots \mathrm{O}_{2}$ structures discussed in the following sections, the $\mathrm{OO}$ and $\mathrm{OH}$ bond lengths change by no more than $0.004 \AA$ and the $\mathrm{HOH}$ bond angle by less than $0.2^{\circ}$.

Table 1: Equilibrium geometrical parameters ( $\mathrm{R}$ in $\AA, \theta$ in degrees) of $\mathrm{O}_{2}$ and $\mathrm{H}_{2} \mathrm{O}$ along with harmonic vibrational frequencies $\left(\omega\right.$ in $\mathrm{cm}^{-1}$ ) and non-zero IR intensities (in parentheses in $\mathrm{km} \mathrm{mol}^{-1}$ )

\begin{tabular}{|c|c|c|c|c|c|c|}
\hline & $\mathrm{R}(\mathrm{OO})$ & $\omega$ & $\mathrm{R}(\mathrm{OH})$ & $\theta(\mathrm{HOH})$ & $\omega_{2}$ & $\omega_{3}$ \\
\hline UMP2/haTZ & 1.224 & 1454.7 & 0.961 & 104.1 & $3824.5(7.6) 1630.1(73.8)$ & $3951.9(75.8)$ \\
\hline UMP2/haQZ & 1.219 & 1479.7 & 0.959 & 104.3 & $3840.5(6.8) 1632.8(73.5)$ & $3966.4(78.5)$ \\
\hline $\mathrm{UCCSD}(\mathrm{T}) / \mathrm{haTZ}$ & 1.213 & 1574.4 & 0.962 & 104.2 & $3813.6(4.6) 1647.9(72.4)$ & $3924.3(54.9)$ \\
\hline $\mathrm{UCCSD}(\mathrm{T}) / \mathrm{haQZ}$ & 1.208 & 1595.7 & 0.959 & 104.4 & $3831.8(4.2) 1650.5(72.5)$ & $3941.4(57.8)$ \\
\hline Experiment $^{a}$ & 1.208 & 1580.2 & 0.957 & 104.5 & $3832.2(3.2) 1648.5 \quad(64)$ & $3942.5(46)$ \\
\hline $\mathrm{QCISD}^{b}$ Ref. [5] & - & 1620.7 & - & - & $3879.8(7.1) 1686.5(65.6)$ & $3982.0(56.1)$ \\
\hline
\end{tabular}

The coupled-cluster equilibrium bond lengths and bond angles obtained with the haQZ basis set are in near perfect agreement with the experimental values for both $\mathrm{O}_{2}[30]$ and $\mathrm{H}_{2} \mathrm{O}$ [31] provided in the last row of Table 1. For water, the experimental and coupled-cluster haQZ harmonic vibrational frequencies do not differ by more than $2.0 \mathrm{~cm}^{-1}$. In contrast the UMP2 results deviate from the experimental values by roughly $10-20 \mathrm{~cm}^{-1}$ for $\mathrm{H}_{2} \mathrm{O}$. The high-spin open-shell $\mathrm{O}_{2}$ system is a bit more challenging, but the experimental harmonic vibrational frequency still falls between the $\operatorname{UCCSD}(\mathrm{T}) /$ haTZ and $\operatorname{UCCSD}(\mathrm{T}) /$ haQZ results whereas the UMP2 method underestimates the frequency by $100 \mathrm{~cm}^{-1}$ or more with both basis sets. Interestingly, the QCISD $/ 6-311++\mathrm{G}(2 d, 2 p)$ harmonic frequencies reported in the supporting information of an earlier study [5] are consistently about $40 \mathrm{~cm}^{-1}$ too large for both $\mathrm{H}_{2} \mathrm{O}$ and $\mathrm{O}_{2}$. The coupledcluster IR intensities are qualitatively consistent with the experimental oscillator strengths. The coupled-cluster intensities computed with the haQZ basis set are within $12 \mathrm{~km} \mathrm{~mol}^{-1}$ of the experimental values (on averge too large by $7 \mathrm{~km}$ $\mathrm{mol}^{-1}$ for the 3 vibrational modes of water). In contrast, the MP2 intensities are appreciably larger for the asymmetric stretch $\left(\omega_{3}\right)$, suggesting the intensity for that mode is nearly identical to that of the bend $\left(\omega_{2}\right)$ which is qualitatively different than experiment.

\subsection{Nature and Structures of the Dimer}

The structures in Figure 1 are shown in the order of increasing electronic energy at the UMP2/haQZ level of theory, with I as the global minimum and $\mathrm{XII}$ as the highest energy stationary point. Six $\mathrm{C}_{2 v}$ structures (II, III, VII, XXII) have been considered, one of which is a local minimum (structure VII) on the UMP2 surface. The other six stationary points have $\mathrm{C}_{s}$ symmetry (I, IVVI, VIII, IX), including the global minimum (structure I). Although structure I is consistently identified as the global minimum here and elsewhere $[6,8,11]$, 
some variation in the exact orientation of the $\mathrm{O}_{2}$ fragment relative to $\mathrm{H}_{2} \mathrm{O}$ is observed for this stationary point. As such, the following discussion primarily focuses on the geometrical parameters of structure I. The UCCSD $(\mathrm{T}) /$ haQZ optimized global minimum has intermolecular angles of $\alpha=110^{\circ}$ and $\beta=106^{\circ}$ and an intermolecular separation of $\mathrm{R}_{e q}=2.64 \AA$ (Fig. 1). Using either UMP2 or $\mathrm{UCCSD}(\mathrm{T})$ with a haTZ or haQZ basis, $\alpha$ and $\beta$ change by less than $\pm 10^{\circ}$ for structure I. Similar parameters were reported at the QCISD $/ 6-311++\mathrm{G}(2 d, 2 p)$ level of theory $\left(\alpha=126^{\circ}, \beta=109^{\circ}, \mathrm{R}_{e q}=2.57 \AA\right)$ [5] and from MP2/aug-cc-pVTZ optimizations $\left(\alpha=102^{\circ}, \beta=112^{\circ}, \mathrm{R}_{e q}=2.57 \AA\right)[8,11]$.

Table 2: Number of imaginary frequencies $\mathrm{n}_{i}$

\begin{tabular}{lcccccccccccc}
\multicolumn{110}{c}{ Table 2: Number of imaginary frequencies $\mathrm{n}_{i}$} \\
\hline & I & II & III & IV & V & VI & VII & VIII & IX & X & XI & XII \\
UMP2/haTZ & 0 & 1 & 1 & 0 & 1 & 2 & 0 & 1 & 2 & 2 & 1 & 1 \\
UMP2/haQZ & 0 & 1 & 1 & 1 & 1 & 2 & 0 & 1 & 2 & 2 & 1 & 2 \\
UCCSD(T)/haTZ & 0 & 1 & 1 & 1 & 1 & 2 & 1 & 1 & 2 & 2 & 1 & 2 \\
UCCSD(T)/haQZ & 0 & 1 & 1 & 1 & 1 & 2 & 1 & 1 & 2 & 2 & 1 & 2 \\
\hline
\end{tabular}

Table 2 lists the number of imaginary frequencies associated with structures $\mathrm{I}$ - XII of the $\mathrm{H}_{2} \mathrm{O} \cdots \mathrm{O}_{2}$ complex. One of the most significant features of the data is that the number of minima changes with computational protocol. At the UMP2/haTZ level of theory, three of the stationary points (structures I, IV, and VII) examined in this study are minima. With the larger haQZ basis set, however, structure IV becomes a transition state with an $\mathrm{a}^{\prime \prime}$ imaginary frequency of $37 i \mathrm{~cm}^{-1}$, whereas structure XII changes from a transition state to a second order saddle point $\left(\mathrm{n}_{i}=2\right)$. Structure VII is also a transition state with both the haTZ and haQZ basis sets at the UCCSD(T) level, having a single imaginary frequency with $\mathrm{b}_{2}$ symmetry. The global minimum is structure I, regardless of method or basis set. As can be seen in Table 2, structures II, III, IV, V, VII, VIII and XI are transition states and structures VI, IX, X and XII are second-order saddle points on the $\mathrm{UCCSD}(\mathrm{T}) / \mathrm{haTZ}$ and $\mathrm{UCCSD}(\mathrm{T}) / \mathrm{haQZ}$ surfaces.

Structure VI provides a more extreme example of this sensitivity. Reference 4 reported a minimum $\mathrm{H}_{2} \mathrm{O} \cdots \mathrm{O}_{2}$ structure from MP2 computations with the $6-311++\mathrm{G}(2 d f, 2 p d)$ basis set that had geometrical parameters $\left(\alpha=178^{\circ}, \beta=\right.$ $179^{\circ}, \mathrm{R}_{e q}=2.43 \AA$ ) very similar to those for structure VI at the UMP2/haTZ $\left(\alpha=180^{\circ}, \beta=169^{\circ}, \mathbf{R}_{e q}=2.47 \AA\right)$. However, stucture VI is a second-order saddle point $\left(\mathrm{n}_{i}=2\right)$ at all levels of theory employed in this study while it is a minimum at the $\mathrm{MP} 2 / 6-311++\mathrm{G}(2 d f, 2 p d)$ level of theory regardless of whether the core electrons are correlated or not. Although structure I was not considered in Reference 4, it remains a lower-energy minimum on the MP2/6$311++\mathrm{G}(2 d f, 2 p d)$ potential energy surface.

Table 3 lists key UMP2/haXZ and $\mathrm{UCCSD}(\mathrm{T}) /$ haXZ $(\mathrm{X}=\mathrm{T}, \mathrm{Q})$ intermolecular separations, $\mathrm{R}_{e q}$, for each optimized structure. Cartesian coordinates, harmonic vibrational frequencies, and IR intensities for every optimized structure are available in the Supplementary Material. The intermolecular separation of 
Table 3: Intermolecular separations $\left(\mathrm{R}_{e q}\right.$ in $\AA$ )

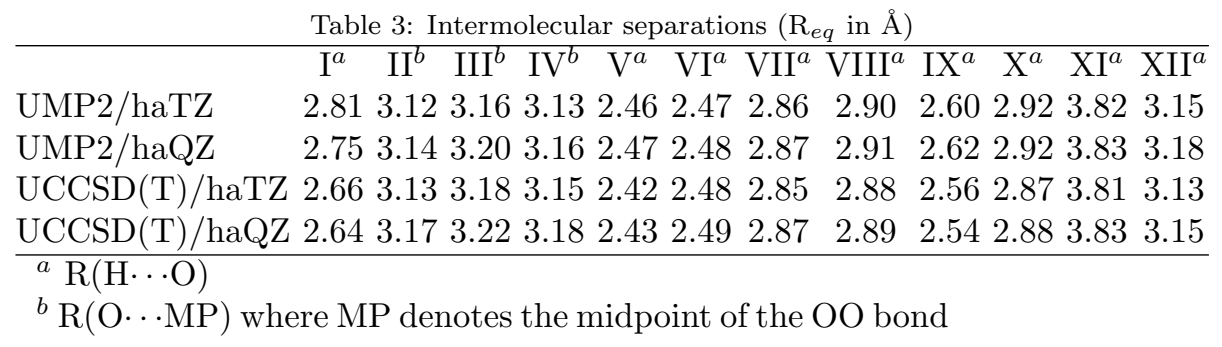

structures II-IV is measured from the midpoint of the $\mathrm{O}_{2}$ bond to the oxygen of $\mathrm{H}_{2} \mathrm{O}$ while $\mathrm{R}_{e q}$ for structures I and V-XII is the shortest intermolecular $\mathrm{O} \cdots \mathrm{H}$ distance (Fig. 1). For structures II-XII, these intermolecular parameters are quite similar regardless of method or basis set used for the optimization, never differing by more than $0.05 \AA$. The global minimum (structure I) has slightly larger deviations $(>0.1 \AA$ ), indicating a large basis and substantial amounts of electron correlation are needed to adequately describe the non-covalent interaction. However, $\mathrm{R}_{e q}$ changes by less than $0.02 \AA$ between $\operatorname{UCCSD}(\mathrm{T}) /$ haTZ and $\mathrm{UCCSD}(\mathrm{T}) /$ haQZ for structure I.

\subsection{Harmonic Vibrational Frequencies and IR Intensities}

As shown in Table 2, structure I is the only minimum at the UCCSD(T) level of theory, and the nature of each stationary point remains consistent with both haTZ and haQZ basis sets. For this reason, after a brief discussion of experimental results, the remainder of this section will focus on the harmonic vibrational frequencies of the global minimum (structure I).

Experimentaly, the ground state of the $\mathrm{H}_{2} \mathrm{O} \cdots \mathrm{O}_{2}$ complex determined via microwave spectroscopy has $\mathrm{C}_{2 v}$ symmetry like that seen in structure II [14]. Computationally, however, structure II is a transition state with an imaginary frequency of $\mathrm{b}_{2}$ symmetry at $40 i \mathrm{~cm}^{-1}$ at the $\operatorname{UCCSD}(\mathrm{T}) /$ haQZ level of theory. A previous study investigated rotations of the $\mathrm{O}_{2}$ and $\mathrm{H}_{2} \mathrm{O}$ fragments in structure I and found the conrotatory motion to be degenerate while the disrotatory motion experiences a slight splitting [8]. That study noted that the transitions between these low-lying states due to the small barrier of the disrotary intermolecular vibration would be interpreted by microwave spectroscopy as a structure with $\mathrm{C}_{2 v}$ symmetry [8].

The UMP2 and UCCSD(T) harmonic vibrational frequencies and IR intensities are listed in Table 4 . Although there is reasonable agreement between the two methods (average absolute deviations of $14 \mathrm{~cm}^{-1}$ and $13 \mathrm{~cm}^{-1}$ for the haTZ and haQZ basis sets, respectively), it is worth noting that the relative order of the $a^{\prime}$ and $a^{\prime \prime}$ intermolecular modes $\left(\omega_{5}\right.$ through $\left.\omega_{9}\right)$ differs. Although an earlier study of mono-hydrated atmospheric species primarily focused on the vibrations of water, QCISD/6-311++G( $2 d, 2 p)$ harmonic vibrational frequencies and IR intensities were reported in the supporting information [5]. Unfortunately, direct comparison to that data is not straightforward because the symmetry 
Table 4: Harmonic vibrational frequencies $\left(\omega\right.$ in $\left.\mathrm{cm}^{-1}\right)$ and IR intensities (in parentheses in $\mathrm{km} \mathrm{mol}^{-1}$ ) of Structure I

\begin{tabular}{|c|c|c|c|c|c|c|c|c|c|}
\hline \multicolumn{2}{|c|}{ Mode } & \multicolumn{2}{|c|}{$\begin{array}{l}\text { UMP2 } \\
\text { haTZ }\end{array}$} & \multicolumn{2}{|c|}{$\begin{array}{l}\text { UMP2 } \\
\text { haQZ }\end{array}$} & \multicolumn{2}{|c|}{$\begin{array}{c}\mathrm{UCCSD}(\mathrm{T}) \\
\text { haTZ }\end{array}$} & \multicolumn{2}{|c|}{$\begin{array}{c}\mathrm{UCCSD}(\mathrm{T}) \\
\text { haQZ }\end{array}$} \\
\hline 1 & $\mathrm{a}^{\prime}$ & 3947.5 & $(73.4)$ & 3962.4 & $(76.4)$ & 3921.8 & $(54.4)$ & 3939.3 & $(58.6)$ \\
\hline$v_{2}$ & $a^{\prime}$ & 19.8 & $(6.3)$ & 3836.2 & $(5.7)$ & 3810.6 & $(3.2)$ & 3829.1 & $(2$. \\
\hline$y_{3}$ & $a^{\prime}$ & 1642.4 & $(70.7)$ & 1639.9 & $(78.2)$ & 1645.2 & $(95.0)$ & 1647.7 & $(93.6)$ \\
\hline$\nu_{4}$ & $a^{\prime}$ & 1574.3 & (19.0) & 1577.4 & (11.9) & 1582.9 & $(0.3)$ & 1601.3 & $(0.4)$ \\
\hline$y_{5}$ & $a^{\prime}$ & 127.8 & $(42.5)$ & 108.4 & $(49.6)$ & 85.7 & $(71.5)$ & 83.5 & $(73.7)$ \\
\hline 6 & $a^{\prime}$ & 72.7 & $(16.2$ & 74.4 & (17. & 80.5 & $(9.5)$ & 78.7 & $(4.9)$ \\
\hline$y_{7}$ & $a^{\prime}$ & 48.6 & $(28.7)$ & 45.8 & $(22.6)$ & 47.3 & (13.9) & 41.3 & $(17.2)$ \\
\hline 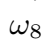 & $a^{\prime \prime}$ & 117.4 & $(0.7)$ & 111.3 & $(3.4)$ & 103.7 & $(4.4)$ & 103.2 & $(<0.1)$ \\
\hline$\nu_{9}$ & $a^{\prime \prime}$ & 86.4 & $(225.5)$ & 79.7 & $(217.5)$ & 71.7 & $(214.8)$ & 67.5 & $(215.5)$ \\
\hline
\end{tabular}

of the vibrational modes was not specified. We repeated the QCISD computations to obtain this information. While these computations exactly matched the frequencies and intensities for the fragments (Table 1), they yielded completely different values for the complex even though the electronic energies match to 0.3 $\mu E_{h}$. Both sets of QCISD/6-311++G(2d,2p) results are provided in the Supplementary Material accompanying this paper where differences approaching 20 $\mathrm{cm}^{-1}$ and $40 \mathrm{~km} \mathrm{~mol}^{-1}$ can be seen. When compared to the UCCSD(T)/haQZ frequencies, the performance of the UMP2 and QCISD methods are comparable in terms of their average and maximum absolute deviations.

Frequency shifts and IR intensities can often provide the means to spectroscopically identify non-covalent complexes. For the global minimum at the UMP2/haQZ level of theory, there is a substantial shift $\left(+98 \mathrm{~cm}^{-1}\right)$ and slight increase in the IR intensity (from 0 to $12 \mathrm{~km} \mathrm{~mol}^{-1}$ ) for the $\mathrm{OO}$ stretch in the dimer at $1577 \mathrm{~cm}^{-1}$, which can be seen in Table 4 . The OO stretch is strongly coupled to the $\mathrm{HOH}$ bend on the UMP2 surface. However, the frequency shift decreases to only $+6 \mathrm{~cm}^{-1}$ and the mode remains IR inactive on the $\operatorname{UCCSD}(\mathrm{T}) / \mathrm{haQZ}$ surface $\left(1601.3 \mathrm{~cm}^{-1}\right.$ and $\left.<1 \mathrm{~km} \mathrm{~mol}^{-1}\right)$. At the $\mathrm{UCCSD}(\mathrm{T}) /$ haQZ level of theory, the mode associated with $\mathrm{HOH}$ bend shifts by close to $-3 \mathrm{~cm}^{-1}$ and has an increase in IR intensity of $+21 \mathrm{~km} \mathrm{~mol}^{-1}$. The changes are even smaller for the symmetric and asymmetric $\mathrm{OH}$ stretches of $\mathrm{H}_{2} \mathrm{O}$, not exceeding $\pm 3 \mathrm{~cm}^{-1}$ and $\pm 1 \mathrm{~km} \mathrm{~mol}^{-1}$. As such, the $\mathrm{HOH}$ bend is the only intramonomer mode with any appreciable increase in IR intensity (from 73 to $94 \mathrm{~km} \mathrm{~mol}^{-1}$, almost $29 \%$ ).

By inspecting the far IR (less than $150 \mathrm{~cm}^{-1}$ ) intermolecular modes of the $\mathrm{H}_{2} \mathrm{O} \cdots \mathrm{O}_{2}$ system, another potential mechanism leading to green house effects can be evaluated. Structure I has five modes in this region (Table 4). However, only two modes have substantial IR intensities at the $\operatorname{UCCSD}(\mathrm{T}) /$ haQZ level of theory. One a' mode is moderately IR active and has an intensity of $74 \mathrm{~km}$ $\mathrm{mol}^{-1}$ at $84 \mathrm{~cm}^{-1}$. The largest IR intensity corresponds to the lowest energy mode of a" symmetry at $68 \mathrm{~cm}^{-1}$ and with an intensity of $216 \mathrm{~km} \mathrm{~mol}^{-1}$, more than double the IR intensity of any other inter- or intramolecular mode 
of the $\mathrm{H}_{2} \mathrm{O} \cdots \mathrm{O}_{2}$ global minimum. By way of comparison, analogous frequency computations on $\left(\mathrm{H}_{2} \mathrm{O}\right)_{2}$ indicate that the lowest-energy intermolecular mode has appreciably higher energy $\left(126.1 \mathrm{~cm}^{-1}\right)$ and less than half the IR intensity (ca. $90.7 \mathrm{~km} \mathrm{~mol}^{-1}$ ) [33].

\subsection{Energetics}

Relative electronic energies of structures I-XII with respect to the global minimum (structure I) are listed in Table 5. In addition to UMP2/haXZ and $\mathrm{UCCSD}(\mathrm{T}) /$ haXZ energies, ROMP2 and $\operatorname{ROCCSD}(\mathrm{T})$ single point computations were performed based on the corresponding UMP2/haXZ or UCCSD(T)/ haXZ optimized geometry. Explicitly correlated UCCSD(T)-F12 and ROCCSD (T)-F12 energies at $\mathrm{UCCSD}(\mathrm{T}) /$ haQZ optimized geometries were included to probe convergence to the CBS limit. It is readily apparent from Table 5 that the potential energy surface is extremely flat with all relative electronic energies within $0.5 \mathrm{kcal} \mathrm{mol}^{-1}$ of the global minimum for structures II-XII. Energetically, increasing the basis set from haTZ to haQZ has little effect, less than $0.05 \mathrm{kcal}$ $\mathrm{mol}^{-1}$ for UMP2 or UCCSD(T). As expected from the diradical nature of $\mathrm{O}_{2}$ and $\mathrm{H}_{2} \mathrm{O} \cdots \mathrm{O}_{2}$, the energetics are more sensitive to electron correlation than basis set effects with maximum deviations of $0.08 \mathrm{kcal} \mathrm{mol}^{-1}$ when comparing $\mathrm{UMP} 2$ to $\operatorname{UCCSD}(\mathrm{T})$.

The spin formalism has a noticeable affect on the MP2 results. ROMP2 underestimates the relative electronic energies by more than $0.1 \mathrm{kcal} \mathrm{mol}^{-1}$ in some cases. In contrast, the spin restricted and unrestricted coupled-cluster results are virtually indistinguishable. ROCCSD $(\mathrm{T}) / \mathrm{haXZ}$ and $\operatorname{UCCSD}(\mathrm{T}) /$ haXZ have deviations less than $0.01 \mathrm{kcal} \mathrm{mol}^{-1}$. UCCSD(T)-F12/ha5Z and ROCCSD(T)F12/ha5Z differ by no more than $0.02 \mathrm{kcal} \mathrm{mol}^{-1}$. The $T_{1}$ and $D_{1}$ diagnostics [34] from these explicitly correlated coupled-cluster computations with the ha5Z basis set never exceed 0.01 and 0.02 , respectively.

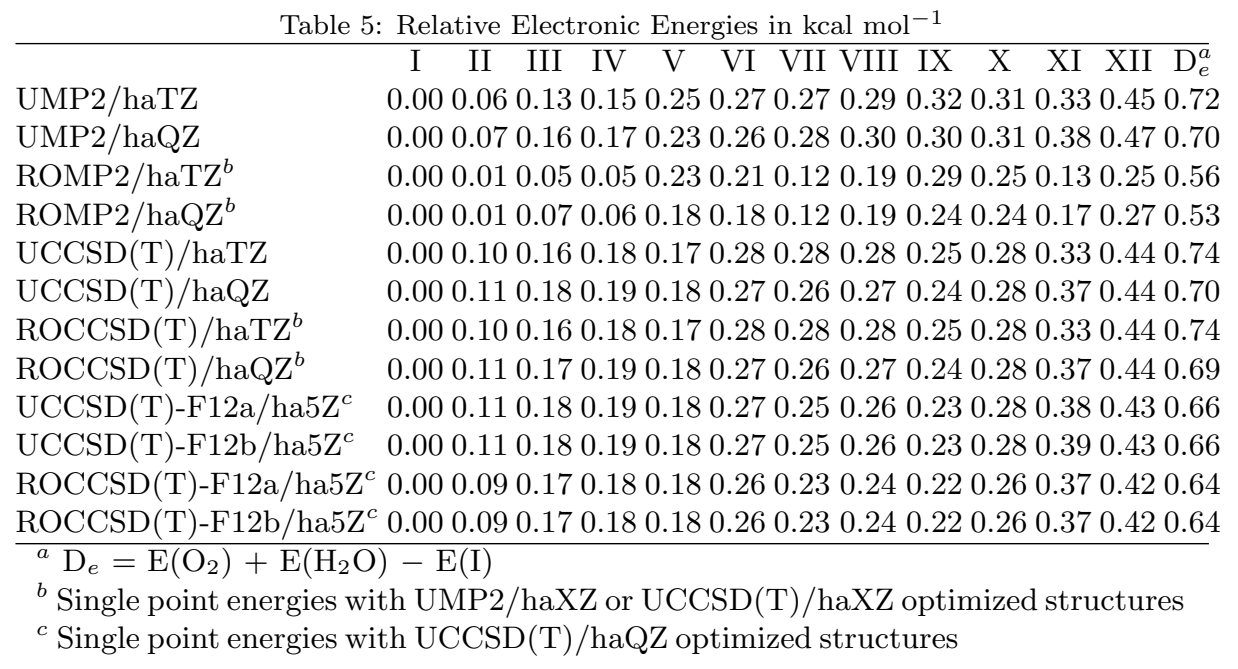


The deviations between $\mathrm{UCCSD}(\mathrm{T}) /$ haQZ and UCCSD(T)-F12/ha5Z relative electronic energies are less than $0.02 \mathrm{kcal} \mathrm{mol}^{-1}$, indicating that this property is well converged to the CBS limit. The electronic dissociation energies $\left(\mathrm{D}_{e}\right.$, the energy of the fully optimized isolated monomers relative to structure I) obtained with the explicitly correlated methods, tend to be about $0.04 \mathrm{kcal} \mathrm{mol}^{-1}$ smaller than the corresponding $\mathrm{UCCSD}(\mathrm{T}) / \mathrm{haQZ}$ and $\operatorname{ROCCSD}(\mathrm{T}) / \mathrm{haQZ}$ results. $\mathrm{D}_{e}$ is $0.70 \mathrm{kcal} \mathrm{mol}^{-1}$ on both UMP2/haQZ and $\mathrm{UCCSD}(\mathrm{T}) / \mathrm{haQZ}$ surfaces, which decreases to $\approx 0.65 \mathrm{kcal} \mathrm{mol}^{-1}$ according to the explicitly correlated coupled-cluster computations. Previous estimates from MP2/aug-cc-pVTZ and QCISD/6-311++G $(2 d, 2 p)$ computations are nearly identical, predicting slightly larger energies of 0.76 and $0.72 \mathrm{kcal} \mathrm{mol}^{-1}$, respectively $[5,8,11]$. Correcting the $\mathrm{UCCSD}(\mathrm{T}) /$ haQZ electronic dissociation energy with the harmonic zero-point vibrational energy, yields a $\mathrm{D}_{0}$ value of $0.17 \mathrm{kcal} \mathrm{mol}^{-1}$. Interestingly, the dimer is slightly unbound on the UMP2/haQZ surface $\left(D_{0}=-0.04 \mathrm{kcal} \mathrm{mol}^{-1}\right)$, but both values would certainly change if anharmonic effects were evaluated.
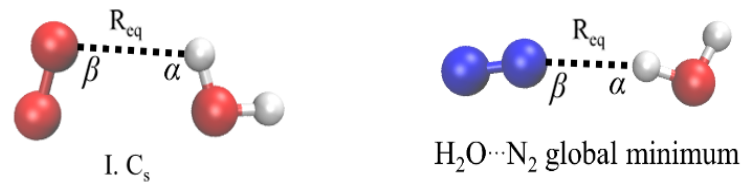

$\mathrm{H}_{2} \mathrm{O} \cdots \mathrm{N}_{2}$ global minimum

Figure 2: Global minima of the $\mathrm{H}_{2} \mathrm{O} \cdots \mathrm{O}_{2}$ (left) and $\mathrm{H}_{2} \mathrm{O} \cdots \mathrm{N}_{2}$ (right) dimers along with select intermolecular geometrical parameters $\left(\mathrm{R}_{e q}, \alpha, \beta\right)$ described in the text.

\subsection{Comparison to $\mathrm{H}_{2} \mathrm{O} \cdots \mathrm{N}_{2}$}

The results obtained in this study for the $\mathrm{H}_{2} \mathrm{O} \cdots \mathrm{O}_{2}$ global minimum brings up several interesting points of divergence with the related $\mathrm{H}_{2} \mathrm{O} \cdots \mathrm{N}_{2}$ van der Waals system (Fig. 2). The following section compares and contrasts geometrical parameters, harmonic vibrational frequencies, IR intensities, and energetics of the $\mathrm{H}_{2} \mathrm{O} \cdots \mathrm{O}_{2}$ global minimum to those of the $\mathrm{H}_{2} \mathrm{O} \cdots \mathrm{N}_{2}$ global minimum.

Geometrically, the global minimum of the $\mathrm{H}_{2} \mathrm{O} \cdots \mathrm{N}_{2}$ complex has the greatest similarity to structure VI of the $\mathrm{H}_{2} \mathrm{O} \cdots \mathrm{O}_{2}$ system, a second-order saddle point on the UCCSD $(\mathrm{T}) /$ haQZ surface. The $\operatorname{CCSD}(\mathrm{T}) /$ haQZ intermolecular arrangement of the $\mathrm{H}_{2} \mathrm{O} \cdots \mathrm{N}_{2}$ minimum is more linear, with both $\alpha$ and $\beta$ (Fig. 2) near $170^{\circ}$ compared to roughly $110^{\circ}$ in the $\mathrm{H}_{2} \mathrm{O} \cdots \mathrm{O}_{2}$ global minimum. $\mathrm{R}_{e q}$ of the $\mathrm{H}_{2} \mathrm{O} \cdots \mathrm{N}_{2}$ global minimum is $2.35 \AA$, nearly $0.3 \AA$ shorter than the corresponding intermolecular separation in structure $\mathrm{I}$ of the $\mathrm{H}_{2} \mathrm{O} \cdots \mathrm{O}_{2}$ system [7].

Although the potential energy surface of $\mathrm{H}_{2} \mathrm{O} \cdots \mathrm{N}_{2}$ is also quite flat, no discrepencies in the number of imaginary frequencies were observed for any structure when using the same basis sets and comparable electronic structure methods. As with $\mathrm{H}_{2} \mathrm{O} \cdots \mathrm{O}_{2}$, frequency shifts upon complexation are small according to coupled-cluster computations, although the associated IR intensity changes are generally larger for $\mathrm{H}_{2} \mathrm{O} \cdots \mathrm{N}_{2}$ (e.g., roughly $+60 \mathrm{~km} \mathrm{~mol}^{-1}$ and 
$+20 \mathrm{~km} \mathrm{~mol}^{-1}$ for the asymmetric and symmetric $\mathrm{OH}$ stretches, respectively) [7]. The global minimum of $\mathrm{H}_{2} \mathrm{O} \cdots \mathrm{N}_{2}$ has only a single intermolecular mode in the far IR with moderate IR intensity on the $\operatorname{CCSD}(\mathrm{T}) /$ haQZ surface: an a' mode at $165 \mathrm{~cm}^{-1}$ with an intensity of $81 \mathrm{~km} \mathrm{~mol}^{-1}$, which is smaller than that of the intramolecular $\mathrm{OH}$ asymmetric stretch $\left(117 \mathrm{~km} \mathrm{~mol}^{-1}\right)$ [7]. In contrast, the $\mathrm{H}_{2} \mathrm{O} \cdots \mathrm{O}_{2}$ complex, has an a" intermolecular mode at $68 \mathrm{~cm}^{-1}$ with an IR intensity of $216 \mathrm{~km} \mathrm{~mol}^{-1}$ which is more than two times larger than that of any other mode.

The global minimum of the $\mathrm{H}_{2} \mathrm{O} \cdots \mathrm{N}_{2}$ system has a dissociation energy of $1.22 \mathrm{kcal} \mathrm{mol}^{-1}$ at the CCSD(T) CBS limit estimated from CCSD(T)-F12/ha5Z computations. Comparitively, structure $\mathrm{I}$ of $\mathrm{H}_{2} \mathrm{O} \cdots \mathrm{O}_{2}$ has a $\mathrm{CCSD}(\mathrm{T}) \mathrm{CBS}$ $\mathrm{D}_{e}$ of $0.65 \mathrm{kcal} \mathrm{mol}^{-1}$ estimated from ROCCSD(T)-F12/ha5Z and UCCSD(T)F12/ha5Z explicitly correlated coupled-cluster computations.

\section{Conclusions}

To summarize the results of this research, structure I is the only minimum on the UCCSD $(\mathrm{T}) /$ haQZ surface out of the twelve $\mathrm{H}_{2} \mathrm{O} \cdots \mathrm{O}_{2}$ stationary points examined. The global minimum has an electronic dissociation energy of approximately $0.65 \mathrm{kcal} \mathrm{mol}^{-1}$ near the $\mathrm{CCSD}(\mathrm{T}) \mathrm{CBS}$ limit. According to coupledcluster theory, there were no significant frequency shifts, IR intensity changes, or geometrical changes of the fragments upon complexation. Although the UMP2 energetics are similar to those from coupled-cluster computations, the method incorrectly identifies two structures as minima. In addition, the UMP2 results suggest the OO harmonic frequency shift upon complexation is substantially larger (ca. $+100 \mathrm{~cm}^{-1}$ ) than the $\operatorname{UCCSD}(\mathrm{T})$ value $\left(\mathrm{ca} .+5 \mathrm{~cm}^{-1}\right)$. Both methods indicate there are two intermolecular modes (one $\mathrm{a}^{\prime}$ and one $\mathrm{a}^{\prime \prime}$ ) with appreciable IR intensity in the far IR region. The IR intensity of the lowest a" mode exceeds $200 \mathrm{~km} \mathrm{~mol}^{-1}$, which is more than double the largest IR intensity of any other mode. Even though the related $\mathrm{H}_{2} \mathrm{O} \cdots \mathrm{N}_{2}$ complex is more strongly bound, it does not possess any intermolecular vibrational modes with IR intensities as large as those seen here for the $\mathrm{H}_{2} \mathrm{O} \cdots \mathrm{O}_{2}$ system.

\section{Acknowledgements}

This work was supported in part by the National Science Foundation (EPS0903787, CHE-1338056). The Mississippi Center for Supercomputing Research (MCSR) also provided a generous allocation of time on their resources. Katelyn Mae Dreux would also like to thank Thomas Ellington for helpful discussions concerning and additional data for the $\mathrm{H}_{2} \mathrm{O} \cdots \mathrm{N}_{2}$ system. The authors also thank Coleman Howard for providing the IR intesities associated with the $\operatorname{CCSD}(\mathrm{T}) /$ haQZ harmonic vibrational frequencies reported in Reference [33]

\section{Appendix A. Supplementary Material}

Supplementary data associated with this article can be found, in the online version, at http://dx.doi.org/x. 


\section{References}

[1] Christopher J. Poulsen, Clay Tabor, and Joseph D. White. Longterm climate forcing by atmospheric oxygen concentrations. Science, 348(6240):1238-1241, 2015.

[2] Robert Kalescky, Wenli Zou, Elfi Kraka, and Dieter Cremer. Local vibrational modes of the water dimer - comparison of theory and experiment. Chem. Phys. Lett., 554:243-247, 2012.

[3] Veronica Vaida, John S. Daniel, Henrik G. Kjaergaard, Lisa M. Goss, and Adrian F. Tuck. Atmospheric absorption of near infrared and visible solar radiation by the hydrogen bonded water dimer. Quarterly Journal of the Royal Meteorological Society, 127(575):1627-1643, 2001.

[4] Igor M. Svishchev and Russell J. Boyd. van der waals complexes of water with oxygen and nitrogen: Infrared spectra and atmospheric implications. J. Phys. Chem. A., 102:7294-7296, 1998.

[5] Henrik G. Kjaergaard, Timothy W. Robinson, Daryl L. Howard, John S. Daniel, Jill E. Headrick, and Veronica Vaida. Complexes of importance to the absorption of solar radiation. J. Phys. Chem. A, 107:10680-10686, 2003.

[6] Henrik G. Kjaergaard, Geoffrey R. Low, Timothy W. Robinson, and Daryl L. Howard. Calculated $\mathrm{OH}$-stretching vibrational transitions in the water-nitrogen and water-oxygen complexes. J. Phys. Chem. A, 106:89558962, 2002.

[7] Thomas L. Ellington and Gregory S. Tschumper. Anchoring the potential energy surface of the nitrogen/water dimer, $\mathrm{H}_{2} \mathrm{O} \cdots \mathrm{N}_{2}$, with explicity correlated coupled-cluster computations. Comput. Theo. Chem., 1021:109113, 2013.

[8] Akiyoshi Sabu, Satomi Kondo, Nobuaki Miura, and Kenro Hashimoto. Potential energy surface and intermolecular vibrations of $\mathrm{O}_{2}-\mathrm{H}_{2} \mathrm{O}$. Chem. Phys. Lett., 391:101-105, 2004.

[9] Zdenek Slanina, Filip Uhlik, Shyi-Long Lee, and Shigeru Nagase. Computational modelling for the clustering degree in the saturated steam and the water-containing complexes in the atmosphere. J. Quant. Spectrosc. Radiat. Transfer, 97:415-423, 2005.

[10] Jewel A. G. Gomes, John L. Gossage, Harimadhav Balu, Mehmet Kesmez, Ferrel Bowen, Richard S. Lumpkin, and David L. Cocke. Experimental and theoretical study of the atmospherically important $\mathrm{O}_{2} \mathrm{H}_{2} \mathrm{O}$ complex. Spectrochim. Acta, Part A, 61A:3082-3086, 2005. 
[11] Akiyoshi Sabu, Satomi Kondo, Ryu Saito, Yasuko Kasai, and Kenro Hashimoto. Theoretical study of $\mathrm{O}_{2}-\mathrm{H}_{2} \mathrm{O}$ : Potential Energy Surface, Molecular Vibrations, and Equilibrium Constant at Atmospheric Temperatures. J. Phys. Chem. A, 109:1836-1842, 2005.

[12] Zdenek Slanina and Filip Uhlik. Clustering, saturated vapors, and the atmosphere: The $\left(\mathrm{H}_{2} \mathrm{O}\right)_{n}, \mathrm{H}_{2} \mathrm{O}-\mathrm{N}_{2}$, and $\mathrm{H}_{2} \mathrm{O}-\mathrm{O}_{2}$ cases. NATO Sci. Ser. IV, 27:101-110, 2003.

[13] Larry A. Curtiss and Carlos A. Melendres. A theoretical study of the solvation of oxygen in water. J. Phys. Chem., 88:1325-1329, 1984.

[14] Yasuko Kasai, Ryu Saito, Kenro Hashimoto, Satomi Kondo, Yoshihiro Sumiyoshi, and Yasuki Endo. The $\mathrm{H}_{2} \mathrm{O}-\mathrm{O}_{2}$ water vapour complex in earth's atmosphere. Atmos. Chem. Phys., 11:8607-8612, 2011.

[15] Patricia R. B. Barreto, Alessandra F. Albernaz, Amedeo Capobianco, Federico Palazzetti, Andrea Lombardi, Gaia Grossi, and Vincenzo Aquilanti. Potential energy surfaces for interactions of $\mathrm{H}_{2} \mathrm{O}$ with $\mathrm{H}_{2}, \mathrm{~N}_{2}$ and $\mathrm{O}_{2}$ : A hyperspherical harmonics representation, and a minimal model for the $\mathrm{H}_{2} \mathrm{O}$-rare-gas-atom systems. Comput. Theor. Chem., 990:53-61, 2012.

[16] Richard J. Wheatley and Allan H. Harvey. The water-oxygen dimer: Firstprinciples calculation of an extrapolated potential energy surface and second virial coefficients. J. Chem. Phys., 127:1-8, 2007.

[17] Richard J. Wheatley and Timothy C. Lillestolen. Calculating intermolecular potentials with simper: the water-nitrogen and water-oxygen interactions, dispersion energy coefficients, and preliminary results for larger molecules. Int. Rev. Phys. Chem., 26:449-485, 2007.

[18] Paul D. Cooper, Henrik G. Kjaergaard, Vaughan S. Langford, Allan J. McKinley, Terence I. Quickenden, Timothy W. Robinson, and Daniel P. Schofield. Infrared identification of matrix isolated $\mathrm{H}_{2} \mathrm{O} \cdot \mathrm{O}_{2}$. J. Phys. Chem. A, 109:4274-4279, 2005.

[19] Andrew J. Bell and Timothy G. Wright. Structures and binding energies of $\mathrm{O}_{2}-\mathrm{H}_{2} \mathrm{O}$ and $\mathrm{O}_{2} \mathrm{H}_{2} \mathrm{O}$. Phys. Chem. Chem. Phys., 6:4385-4390, 2004.

[20] Timothy W. Robinson and Henrik G. Kjaergaard. High level ab initio studies of the low-lying excited states in the $\mathrm{H}_{2} \mathrm{O} \cdot \mathrm{O}_{2}$ complex. J. Chem. Phys., 119:3717-3720, 2003.

[21] Veronica Vaida and Jill E. Headrick. Physicochemical properties of hydrated complexes in the earth's atmosphere. J. Phys. Chem. A, 104(23):5401-5412, 2000.

[22] Mark A. Vincent and Ian H. Hillier. Structures on the singlet and triplet $\mathrm{O}_{3} \mathrm{H}_{2}$ potential energy surfaces: Implications for photonucleation of water in the presence of molecular oxygen. J. Phys. Chem., 99:3109-3113, 1995. 
[23] C. Møller and M. S. Plesset. Note on an approximation treatment for many-electron systems. Phys. Rev., 46:618, 1934.

[24] G.D. Purvis and R.J. Bartlett. A full coupled-cluster singles and doubles model: The inclusion of disconnected triples. J. Chem. Phys., 76(4):1910, 1982.

[25] J.F. Stanton, J. Gauss, M.E. Harding, P.G. Szalay with contributions from A.A. Auer, R.J. Bartlett, U. Benedikt, C. Berger, D.E. Bernholdt, Y.J. Bomble, L. Cheng, O. Christiansen, M. Heckert, O. Heun, C. Huber, T.-C. Jagau, D. Jonsson, J. Jusélius, K. Klein, W.J. Lauderdale, D.A. Matthews, T. Metzroth, L.A. Mück, D.P. O’Neill, D.R. Price, E. Prochnow, K. Ruud, F. Schiffmann, W. Schwalbach, S. Stopkowicz, A. Tajti, J. Vázquez, F. Wang, J.D. Watts, the integral packages MOLECULE (J. Almlöf, P.R. Taylor), PROPS (P.R. Taylor), ABACUS (T. Helgaker, H.J. Aa. Jensen, P. Jørgensen, J. Olsen), ECP routines by A. V. Mitin, and C. van Wüllen. For the current version see http://www.cfour.de.

[26] H.-J. Werner, P. J. Knowles, F. R. Manby, M. Schütz, P. Celani, G. Knizia, T. Korona, R. Lindh, A. Mitrushenkov, G. Rauhut, T. B. Adler, R. D. Amos, A. Bernhardsson, A. Berning, D. L. Cooper, M. J. O. Deegan, A. J. Dobbyn, F. Eckert, E. Goll, C. Hampel, A. Hesselmann, G. Hetzer, T. Hrenar, G. Jansen, C. Köppl, Y. Liu, A. W. Lloyd, R. A. Mata, A. J. May, S. J. McNicholas, W. Meyer, M. E. Mura, A. Nicklass, P. Palmieri, K. Pflüger, R. Pitzer, M. Reiher, T. Shiozaki, H. Stoll, A. J. Stone, R. Tarroni, T. Thorsteinsson, M. Wang, and A. Wolf. Molpro, version 2010.1, a package of ab initio programs, 2010.

[27] Peter J. Knowles, Claudia Hampel, and Hans-Joachim Werner. Coupled cluster theory for high spin, open shell reference wavefunctions. J. Chem. Phys., 99:7294-7296, 1993.

[28] Gerald Knizia, Thomas B. Adler, and Hans-Joachim Werner. Simplified CCSD(T)-F12 methods: Theory and benchmarks. J. Chem. Phys., 130:1$20,2009$.

[29] M. J. Frisch, G. W. Trucks, H. B. Schlegel, G. E. Scuseria, M. A. Robb, J. R. Cheeseman, G. Scalmani, V. Barone, B. Mennucci, G. A. Petersson, H. Nakatsuji, M. Caricato, X. Li, H. P. Hratchian, A. F. Izmaylov, J. Bloino, G. Zheng, J. L. Sonnenberg, M. Hada, M. Ehara, K. Toyota, R. Fukuda, J. Hasegawa, M. Ishida, T. Nakajima, Y. Honda, O. Kitao, H. Nakai, T. Vreven, Jr. J. A. Montgomery, J. E. Peralta, F. Ogliaro, M. Bearpark, J. J. Heyd, E. Brothers, K. N. Kudin, V. N. Staroverov, T. Keith, R. Kobayashi, J. Normand, K. Raghavachari, A. Rendell, J. C. Burant, S. S. Iyengar, J. Tomasi, M. Cossi, N. Rega, J. M. Millam, M. Klene, J. E. Knox, J. B. Cross, V. Bakken, C. Adamo, J. Jaramillo, R. Gomperts, R. E. Stratmann, O. Yazyev, A. J. Austin, R. Cammi, C. Pomelli, J. W. Ochterski, R. L. Martin, K. Morokuma, V. G. Zakrzewski, 
G. A. Voth, P. Salvador, J. J. Dannenberg, S. Dapprich, A. D. Daniels, O. Farkas, J. B. Foresman, J. V. Ortiz, J. Cioslowski, and D. J. Fox. Gaussian 09 Revision C.01. Gaussian Inc. Wallingford CT 2010.

[30] K. P. Huber and G. Herzberg. Molecular Spectra and Molecular Structure, IV. Constants of Diatomic Molecules. Van Nostrand Reinhold, New York, 1979.

[31] W. S. Benedict, N. Gailar, and Earle K. Plyler. Rotation-vibration spectra of deuterated water vapor. J. Chem. Phys., 24:1139-1165, 1956.

[32] Henrik G. Kjaergaard, Anna L. Garden, Galina M. Chaban, R. Benny Gerber, Devin A. Matthews, and John F. Stanton. Calculation of vibrational transition frequencies and intensities in water dimer: comparision of different vibrational approaches. J. Phys. Chem. A, 112:4324-4335, 2008.

[33] J. Coleman Howard, Jessica L. Gray, Amanda J. Hardwick, Linh T. Nguyen, and Gregory S. Tschumper. Getting down to the fundamentals of hydrogen bonding: Anharmonic vibrational frequencies of the hetero and homogeneous dimers of $\mathrm{HF}$ and $\mathrm{H}_{2} \mathrm{O}$ from ab initio electronic structure computations. J. Chem. Theory Comput., 10(12):5426-5435, 2014.

[34] Timothy J. Lee. Comparison of the $T_{1}$ and $D_{1}$ diagnostics for electronic structure theory: a new definition for the open-shell $D_{1}$ diagnostic. Chem. Phys. Lett., 372:362-367, 2003. 


\section{Graphical Abstract}

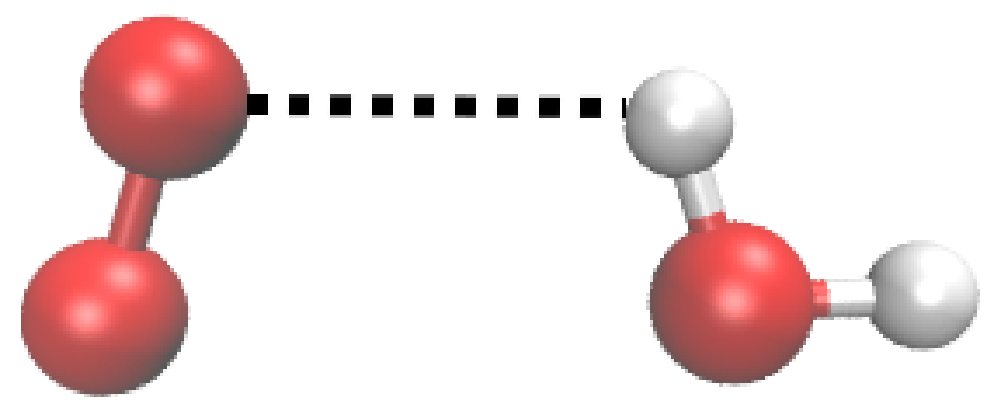

The global minimum on the $\mathrm{H}_{2} \mathrm{O} \cdots \mathrm{O}_{2}$ potential energy surface has been identified with an electronic dissociation energy of $0.65 \mathrm{kcal} \mathrm{mol}^{-1}$ at the UCCSD(T) complete basis set limit. 